\section{Questión}

Periodismo / Comunicación ISSN 1669-6581
- Av. $44 \mathrm{~N}^{\circ} 676,1^{\circ}$ piso

CP 1900 - La Plata - Argentina

www.perio.unlp.edu.ar/question

El extranjero en pandemia

Fernanda González

DOI: https://doi.org/10.24215/16696581e326

\title{
El extranjero en pandemia
}

\section{The foreigner in pandemic}

Escribo desde Malta, una isla ubicada en el mediterráneo en medio de Europa y África o más claro aún, entre Libia e Italia. Vivo en este país hace tres años. Desde entonces han pasado varios sucesos nacionales relevantes: el asesinato de la periodista Dapne Caruana con un carro bomba, Valletta como capital europea de la cultura, el apuñalamiento mortal a Hugo Chetcuti, uno de los empresarios más rico del país, justo al frente de su emporio, y la renuncia del primer ministro, Joseph Muscat, tras la judicialización de su jefe de gabinete por la muerte de Caruana.

Estos hechos mantuvieron a la isla en una conmoción tras otra por un período de tiempo. Hasta ahora fue un lugar dinámico con disputas políticas y sociales comparables con las de cualquier otro país remoto. En estos tiempos, la isla también coincide con el resto del mundo en la extensión de la Pandemia del Covid 19 y en la consigna implícita: cualquiera puede ser sospechoso. Todos podríamos tener el virus, desconfiamos unos de los otros.

En un principio el virus fue enteramente externo, me refiero al origen, un brote con una nacionalidad, poco después se extendió a otras. Luego, ocurrió el señalamiento de quienes procedían de esas nacionalidades, esos eran los sospechosos principales, los que podían esparcir el virus. La distancia social existió mucho antes de ser un mandato gubernamental y 
se rigió entre las personas por la apariencia que tenía el otro, es decir evadir en espacios públicos a quienes tenían ciertos rasgos congénitos.

De ese modo, el primer síntoma social fue el miedo al extranjero o al que venía del exterior, que inicialmente, para el imaginario colectivo, era lo mismo. Supongo que este fenómeno sucedió en Malta y en el resto del planeta, excepto en China donde el miedo de los ciudadanos estuvo dirigido hacia personas de otras provincias. Lo anterior ocurrió en un principio, pues en estos momentos que la curva se aplanó, el miedo se enfoca hacia los que retornan. En China se habla por primera vez de casos importados, el círculo del miedo sucedió a la inversa.

Entonces, cómo habrá pasado en otros recodos del mundo, la idea primaria de que el extranjero era el único portador del virus caló en la sociedad maltesa, incluso cuando es más que evidente que los nacionales también viajan al exterior. En parte, esa idea primó porque en los estudios epidemiológicos resulta útil hablar públicamente de la diferencia entre los casos importados y la transmisión local, en tanto que para la sociedad fue el gancho perfecto para afianzar su temor a lo externo.

A medida que el virus iba extendiéndose por países europeos cercanos, las personas llenaban los supermercados. Sin haber tenido el primer caso, los ecos de las noticias procedentes de Italia iban al ritmo del sonido de las cajas registradoras en Malta. La propagación del virus se acercaba como un río que se salía de cauce para desfigurar el terreno y sacar los desperdicios de la superficie a flote.

El 11 de marzo, cuatro días después del anuncio del paciente 1 en la isla, la primera entidad en cerrar al público sin previo aviso fue la "la unidad de los expatriados", que tramita las aplicaciones de extranjeros para acceder a los diferentes tipos de permisos de residencia: "Identity Malta's expatriate unit was shut without warning on Wednesday morning as workers, fearing the global coronavirus outbreak, told management they felt uncomfortable working with hundreds of foreigners" 1.

En la madrugada de ese mismo día se restringieron los vuelos procedentes de cinco países, hasta que a mediados de marzo el aeropuerto fue cerrado por completo, excepto para vuelos de repatriación.

\footnotetext{
${ }^{1}$ Abela, K. (11 de marzo, 2020). Identity Malta expatriate unit shut over workers' coronavirus fears. Times of Malta. Recuperado de: https://timesofmalta.com/articles/view/identity-malta-offices-remain-shut-prompting-long-queues-inmsida. 777248
} 
Por esos días el ministro de economía, Silvio Schembri 2, manifestó en plenaria que los extranjeros que pierdan su trabajo a causa de las medidas para combatir el virus, deberían regresar a sus países de origen. En su debate, bajo el lema "charity begins at home", expresó que la prioridad era garantizar el trabajo para los malteses. Ante las críticas de la población extranjera, que labora en la isla y de algunos nacionales, tuvo que pedir disculpas por sus palabras. Cambió el discurso hacia el compromiso con todos los trabajadores sin importar la nacionalidad ante el eventual desempleo, que ya es del $20 \%$, según cifras oficiales 3 .

Hasta la fecha, las renovaciones ni nuevas aplicaciones para permisos laborales se encuentran abiertas. El nueve de abril el gobierno maltés ofreció vuelos subsidiados 4 para repatriar a todos los extranjeros en condición de residentes o turistas que desearan regresar a sus naciones, cuando se venció el plazo de inscripción, el tiempo para el registro se extendió hasta el 10 de mayo.

\section{La desigualdad a la calle}

En Malta no ha habido cuarentena obligatoria, a cambio el gobierno optó por tomar algunas restricciones para controlar la propagación del virus. Las medidas fueron puestas en marcha de forma rápida y para datos oficiales hubo una contención admirable en la circulación del virus. A partir del 16 de marzo se implementaron las medidas de cierre que involucraban a las instituciones educativas, restaurantes, bares, discotecas, almacenes y en general, locales comerciales o de servicios no esenciales.

Actualmente solo se encuentran abiertos: los supermercados, farmacias, algunas heladerías y restaurantes, que realizan delivery. Muchas empresas se decidieron por el teletrabajo o por disminuir la presencia de sus empleados en las compañías. Desde mediados de marzo, lo que

\footnotetext{
${ }^{2}$ Micallef, K. (17 de marzo, 2020). Foreigners who lose jobs will 'go back to their country' - minister. Times of Malta. Recuperado de: https://timesofmalta.com/articles/view/governments-priority-is-to-safeguard-jobs-of-maltesenationals.778874\#.XnEOM6PD_7l.facebook

${ }^{3}$ Bonnici, J. (21 de abril, 2020). Unemployment In Malta Rose By 20\% In First Two Weeks Of COVID-19 Closures. Lovin Malta. Recuperado de: https://lovinmalta.com/news/unemployment-in-malta-rose-by-20-in-first-two-weeks-of-covid-19-closures/ ${ }^{4}$ (9 de abril, 2020). Foreigners stranded in Malta invited to apply for repatriation flights. Times of Malta. Recuperado de:https://timesofmalta.com/articles/view/foreigners-stranded-in-malta-invited-to-apply-forrepatriation-flights. 784523
} 
sí se prohibió oficialmente fue que las mujeres embarazadas, los mayores de 65 años y las personas con enfermedades graves fuesen a sus lugares de trabajo.

Dos grandes sectores siguen funcionando plenamente: la Construcción y la industria del entretenimiento virtual, Igaming, áreas indispensables para la economía e incompatibles con el trabajo remoto. La estrategia consistió en que siguieran abiertas esas industrias para mitigar las pérdidas en el $\mathrm{PBI}$ de los otros dos grandes pilares productivos del país, el turismo y las escuelas de inglés con cada uno de sus negocios adyacentes. Todas, áreas dependientes de trabajadores, consumidores o capital extranjero.

Luego de más de un mes de expansión del virus en Malta no se habla más de casos importados, aunque en el detalle diario de los contagiados sí se revela la nacionalidad y la edad. La rueda de prensa se transmite en vivo por la red social Facebook y las primeras semanas se hizo solo en maltés, aún cuando el inglés es también el idioma oficial.

Si bien no existe un confinamiento total, en las calles que no son principales se alcanza a percibir un silencio, especialmente los días de semana. No es el silencio del invierno cuando no hay muchas turistas, tampoco lo es el de los domingos por las tardes ni el silencio de las madrugadas frías. Los locales cerrados dan a ciertas ciudades un aire de marcha fúnebre. Afuera los movimientos son lentos, si aparece un rostro descubierto, no tiene sonrisa y los ojos de los transeúntes miran como interpelando el entorno.

Nunca antes fue tan cierta la frase "tres son multitud"; se crearon multas para quien esté en la calle con dos personas más que no sean familiares entre sí. De hecho, el gobierno decretó infinidades de sanciones relacionadas con las medidas de prevención, incluso al inicio hubo amenaza de deportación para los extranjeros que no siguieran los 14 días de cuarentena, luego del regreso de un viaje en el exterior.

Las bancas en los parques fueron selladas con cinta plástica para evitar que las personas, sobre todo las mayores, se sentaran a tomar el sol, hablar con sus vecinos o ver el día pasar. Los supermercados controlan en la entrada el número de compradores y es común ver filas donde los vigilantes toman la temperatura o aplican alcohol a las manos de los clientes. Además, algunas tiendas de herramientas de ferretería encontraron una oportunidad de venta en productos de aseo o de protección contra el virus.

La desigualdad permanece en tiempos de pandemia y es palpable en las calles. Por un lado, están los que salen por diversión, sobre todo los fines de semana y en las tardes cuando el 
horario del teletrabajo se los permite. Son quienes se aburren en casa y deciden salir a caminar, trotar y visitar las playas o ir en autos hasta las orillas de la isla.

Del otro lado está la población migrante, que se salvó de no perder el empleo. Transitan las calles para dirigirse a sus lugares de trabajo. Ellos también parecen estar en silencio, en reflexión. Caminan con mascarillas improvisadas hacia sus casas o a la parada de buses. Aunque no se puede salir a la calle en grupos, algunos obreros de la construcción lo siguen haciendo, guardando distancia entre ellos.

Los migrantes que trabajan como mano de obra no calificada en su mayoría son filipinos, indios y de países africanos. Estas personas se encuentran a diario en las calles para: atender los supermercados medianos y pequeños, llenar la estantería, descargar el carro de los alimentos, vigilar las empresas o el comercio, asear los lugares que siguen abiertos, recoger la basura para lanzarla al camión, (con pocos implementos de protección), conducir los buses del servicio público, transportar los deliveries, arreglar carros averiados, construir edificos, calles o puentes. No tienen como única elección salir de sus apartamentos compartidos solo por entretenimiento.

Aún estando en mayor riesgo que otros habitantes no están reconocidos en el discurso de los héroes en pandemia porque a primera vista para los ojos de la empatía social o de la cadena de producción no hacen ninguna hazaña extraordinaria5.

En cuanto a los centros de atención a solicitantes de refugio en Malta, se puede resumir la situación diciendo que el mayor de ellos, Hal Far, se encuentra en cuarentena obligatoria con un total de 41 casos positivos, hasta la fecha en la que escribo. Los residentes del centro protestaron y aseguran que las instalaciones no son adecuadas para mantener el distanciamiento social entre las mil personas que se encuentran en el centro.

En el mar la situación es aún más compleja. Los puertos tanto de Italia como de Malta están cerrados desde el nueve de abril porque fueron declarados "unsafe" para desembarcar los botes de migrantes africanos que cruzan el mediterráneo hacia Europa. La última embarcación que llegó a aguas maltesas no fue rescatada sino enviada de regreso a Libia. El gobierno maltés se mantuvo en la posición de que recibir a más migrantes sería poner el riesgo las

\footnotetext{
${ }^{5}$ Sólo en España crearon la campaña \#héroesdeapie en la que se les deja mensajes de agradecimiento a los recolectores de basura.
} 
medidas para combatir el Covid 19. Cinco personas murieron a la espera de que los recibieran y siete fueron reportado como desaparecidos en el mar6.

Sensatez para la post-pandemia

Existen varias preguntas en medio de la pandemia. Una de las más comunes es cómo seguiremos viviendo en comunidad. La relación con los otros cambió, incluso en los países donde no hay una cuarentena estricta y obligatoria. Además, posiblemente algunos de esos cambios perdurarán hasta que se encuentre la vacuna o incluso, después de ella.

Las bondades del distanciamiento social sumadas a la higiene para prevenir el virus fueron replicadas en todas partes del mundo como un mandato. Si lo pensamos como sociedad es indiscutible que unos necesitamos de otros. Los países en una mejor posición económica han tenido a su población con más privilegios gracias a los migrantes (forzados o económicos), que logran permanecer en esas naciones.

En el fondo cada país sabrá cómo ha aprovechado la pobreza o los conflictos de ciertos países para aumentar su riqueza. Algunos serán más evidentes que otros, en general es una táctica económica muy exitosa en la que, por ejemplo, se ubica a la mayoría de los migrantes en empleos con sueldos paupérrimos en sectores importantes a nivel nacional.

Probablemente es un fenómeno que poco se asocia con la agricultura. Es un sector con el que se puede ejemplificar la manera en la que se emplean a ciertos migrantes en trabajos pocos remunerados, no por eso menos importantes. Para algunos puede parecer sorpresivo, pero en varios países hablar de agricultura es también hablar de obra de mano migrante, a pesar de que solo tengamos la idea de que los "empleos de temporada" son solo exclusivos del sector turístico.

La agricultura tiene una relevancia y una ganancia tan evidente para el bienestar nacional que aún en pandemia los gobiernos facilitaron la llegada a Reino Unido (1) y Alemania (11) de

${ }^{6}$ Vella, M._(15 de abril, 2020). Five migrants dead after survivors stranded in Maltese waters are taken to Libya. Malta Today. Recuperado de:

https://www.maltatoday.com.mt/news/national/101720/five_migrants_dead_after_survivors_stranded_in_maltese_water s_are_taken_to libya\#.Xp97i8gzY2w 
vuelos con "recogedores de frutas y vegetales" provenientes de Rumania y Bulgaria 7 para salvar las cosechas o "feed the nation" 8 . Ni hablar de los migrantes indocumentados que trabajan la tierra con salarios irrisorios en España.

Probablemente, tras superar o controlar el Covid 19 el mundo seguirá siendo lo que ya es: desigual como lo está siendo durante la pandemia. Al menos no olvidemos que esta crisis mundial también es la crisis de replanteamientos de conceptos, de modos de vida. Sería, como mínimo, interesante pensar como sociedad que de ahora en adelante en términos de salud cualquier enfermedad que surja en un sitio apartado distinto al nuestro, por lo cultural o lo económico, no podrá ser indiferente para el resto de la humanidad.

Somos vulnerables, en plural. Un solo país difícilmente podrá superar la pandemia y estabilizarse. No es aprender a vivir con el virus a lo que deberíamos apuntar únicamente, sino a aprender a vernos como un todo. Repito, nunca antes como ahora la más lejana epidemia puede entrar en la puerta de nuestras privilegiadas casas. Parece obvio, de todas formas recordemos que las epidemias también podrían surgir por la las condiciones sanitarias, las prácticas agropecuarias, la pobreza o la corrupción, la incapacidad de distribuir los recursos donde deberían estar para salvar al mayor número de personas antes de que la enfermedad sea más resistente o mute.

En otras palabras, los países con mejor posición económica deberían ser menos ambiciosos de lo contrario, las consecuencias de la desigualdad pueden revertirse hacia ellos como quizás ya está pasando. No balancear los recursos, los avances tecnológicos o el conocimiento en general, puede repercutir en la vida de todos sin distinción. Concluyo, compartiendo estos dos ejemplos gráficos de la situación reciente en las calles de Nigeria y en una granja de West Midlands para que además de pedir vacunas para todos asimismo pidamos construir un mundo más justo.

Notas

\footnotetext{
7 Slater, R. (16 de abril, 2020). First plane carrying 150 'critically important' Romanian fruit pickers who will join 'land army' battling to save Britain's harvest lands at Stansted. Daily Mail. Recuperado de: https://www.dailymail.co.uk/news/article-8227101/Plane-carrying-150-fruit-veg-pickers-Romania-lands-Stansted.html 824 de Marzo, 2020. Fruit and veg growers call for workers to 'feed the nation'. BBC News. Recuperado de: https://www.bbc.com/news/uk-england-cambridgeshire-52019810
} 